\title{
Methodology for Vibration Signal Processing of an On-load Tap Changer
}

\author{
Edwin Rivas Trujillo1, \\ Juan C. Burgos Diaz ${ }^{2}$ and Juan C. García-Prada ${ }^{3}$ \\ ${ }_{1}^{1}$ Universidad Distrital Francisco José de Caldas-Facultad de ingeniería \\ Carrera 7 No 40-53 Bogotá \\ ${ }^{2}$ E.P.S Universidad Carlos III de Madrid-Departamento de Ingeniería Eléctrica \\ C/ Butarque 15, 28911Madrid, \\ ${ }^{3}$ E.P.S Universidad Carlos III de Madrid-Departamento de Ingeniería Mecánica \\ C/ Butarque 15, 28911Madrid, \\ ${ }^{1}$ Colombia \\ ${ }^{2,3}$ España
}

\section{Introduction}

A great percentages of transformer failures occur in the on-load tap changer (OLTC) (R. Jongen \& P. Morshuis et al.,2007) Fig 1. The OLTC is the only moving part of a power transformer and its elements suffer from great mechanical and electrical stress.

The condition of some of the elements of the OLTC (diverter switch, resistors, contacts, etc.) can be evaluated through periodic inspections. However, these inspections require having the transformer out of service for a relatively long period. In addition, it is expensive and requires a skilled staff.

Vibration is a suitable parameter to monitor the mechanical condition of an OLTC (P. Kang,et al.,2000). Vibrations from a working OLTC are often readily available, but obtaining them from a defective OLTC is not as easy.

Previous studies (P. Kang et al.,2001) show that OLTC failures can be diagnosed by using vibration envelope analysis. Wavelet analysis is an effective technique for extracting the main characteristics of the vibration signal, over the whole spectrum, without requiring a dominant frequency band in the vibration signal.

The purpose of this paper is to present a methodology implemented to find the OLTC diagnostic indicators (Number of vibration bursts, Vibration burst amplitude, Time between vibration bursts, Main frequency bands in the burst, energy of the vibration bursts). To obtain these indicators pre-processing and processing of the vibration signal is needed.

In the pre-processing stage the signal is synchronized, normalized and then Hilbert transform is applied to obtain the envelope. In the signal processing stage a technique in time-frequency domain, Discrete Wavelet Transform, is used and then a threshold based on 
preserved energy is applied in order to determine the characteristic bursts of the vibration signal both the OLTC in good condition and with faults.

\section{OLTC}

An OLTC (Fig. 1) modify the transformer voltage ratio in response to voltage variations in the electrical system, in order to maintain transformer output voltage. The OLTC changes the tapping connection of the transformer winding without disconnecting it out of service. An OLTC comprises the following elements:

- Tap Selector

- Diverter Switch

An OLTC always switches between two consecutive taps. The tap selector pre-selects the next tap to work on and does not switch load current. The tap selector is inserted in the transformer tank or attached to it, and it is refrigerated by the same oil refrigerating the windings.

The tap selector is driven by a motor drive mechanism synchronized with the diverter switch. The tap selector and the mechanical energy accumulator of the diverter switch are the first elements to move when a tap change is ordered. The tap selector moves only to the tap preceding the current tap or to the tap next the current tap.

The diverter switch is the element transferring the load current, without load interruption, from the current tap to the pre-selected tap.

\section{Vibration signal measurements}

A test program was carried out to get vibration signals with different types of failures. As it is no easy to record in field vibration signals from a given OLTC with different kind of failures, failures were simulated physically in the laboratory.

An OLTC (Fig. 1) type D I 1200 150/110 $12233 \mathrm{~W}$, from an 80 MVA single-phase autotransformer $250.000 / 150.000 \pm 10 \times 1517 / 17000 \mathrm{~V}$ was used. The OLTC is rated at $1200 \mathrm{~A}$ and has 12 taps, 23 regulation positions, an inverter type pre-selector and 3 intermediate positions when the inverter is in operation.

The OLTC was not mounted on the transformer tank and was not immersed in oil. So pattern vibration changes slightly because no viscous lubrication is provided. Nevertheless the experiment is valid in the essence.

The vibration measurements were obtained using an accelerometer, which measures tank vibrations during the tap-change operation. A piezoelectric accelerometer was used with a sensitivity of $1.02 \pm 0.02 \mathrm{pC} / \mathrm{ms}^{2}$ and a frequency range of 1 to $12 \mathrm{kHz}$. The data acquisition card had PCMCIA architecture, 12-bit resolution, 50KS/s per channel and variable input range of $\pm 0.05 \mathrm{~V}$ to $\pm 10 \mathrm{~V}$. The measuring system is shown in Fig. 2.

Vibration signal was recorded from the OLTC in good working condition. Fig. 3 shows the vibration signal during a tap change in which the tap selector is operative. Six bursts can be distinguished in the vibration signal.

- $\quad$ Burst 1: Starting of the motor drive.

- Burst 2: Activation of the Geneva drive. The tap selector contact attached to the previous tap (n-1) starts moving.

- Burst 3: Moving contacts of the tap selector reach the final tap $(n+1)$. 
- $\quad$ Burst 4: The movement of the Geneva drive ends.

- Burst 5: Group of bursts corresponding to the diverter switch's activation.

- $\quad$ Burst 6: The motor drive stops.

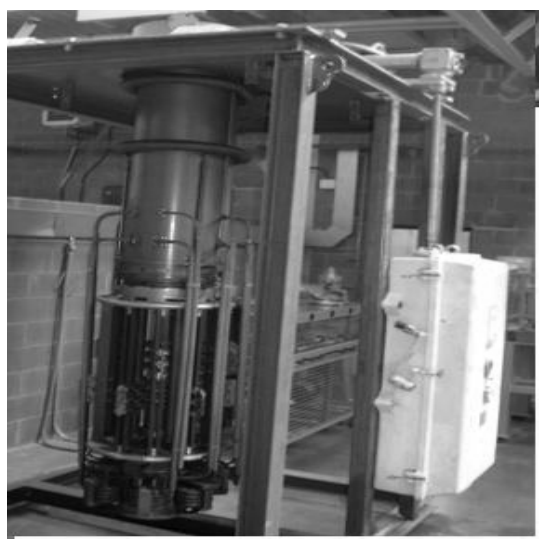

Fig. 1. OLTC used in the experimental measurements

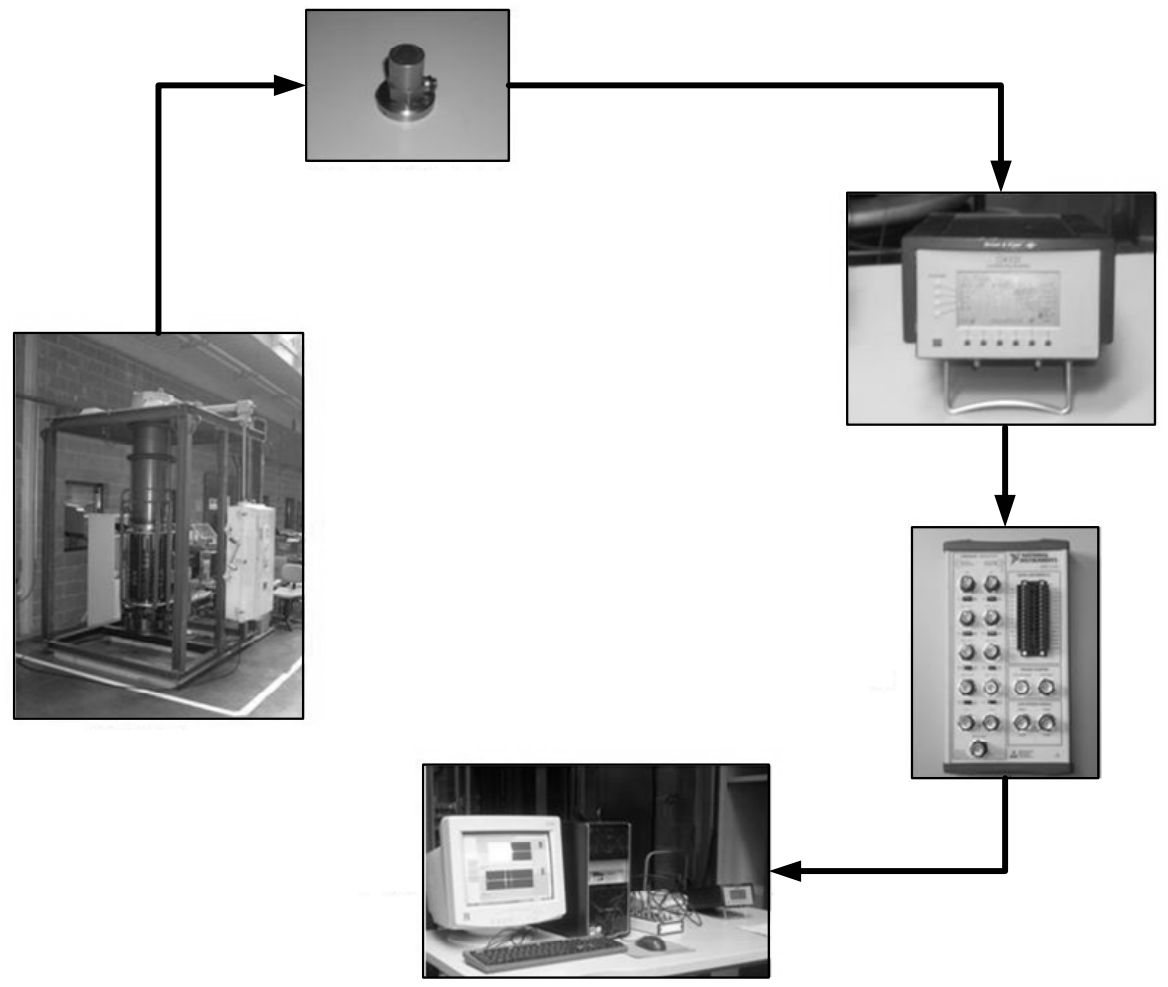

Fig. 2. Measuring system 


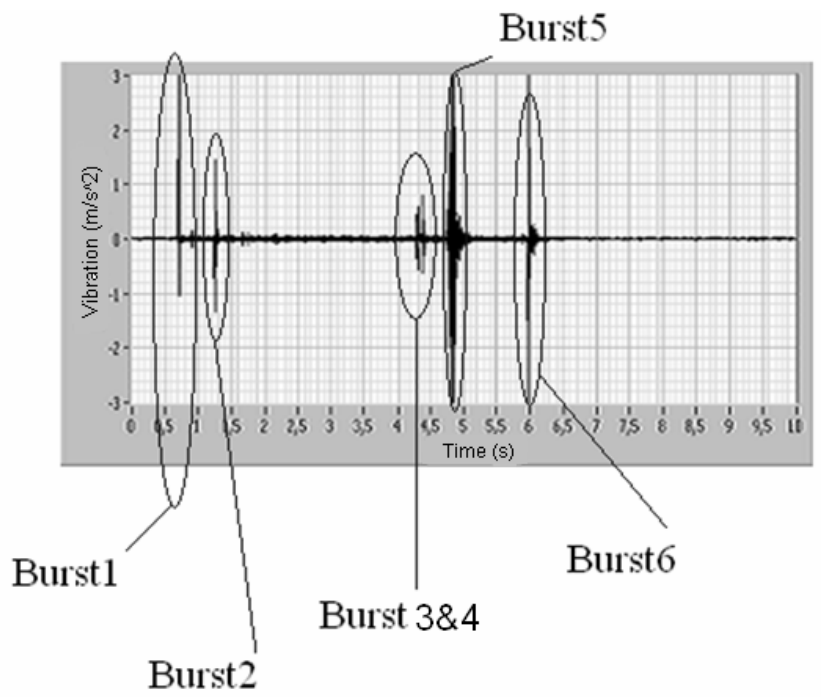

Fig. 3. Vibration signal during a tap change

\section{Test programme}

Some of the failures simulated in the experiment were: Broken contact bar (Fig. 4) and tap selector contacts damaged by arcing (Fig. 5), worn selector contacts, etc.

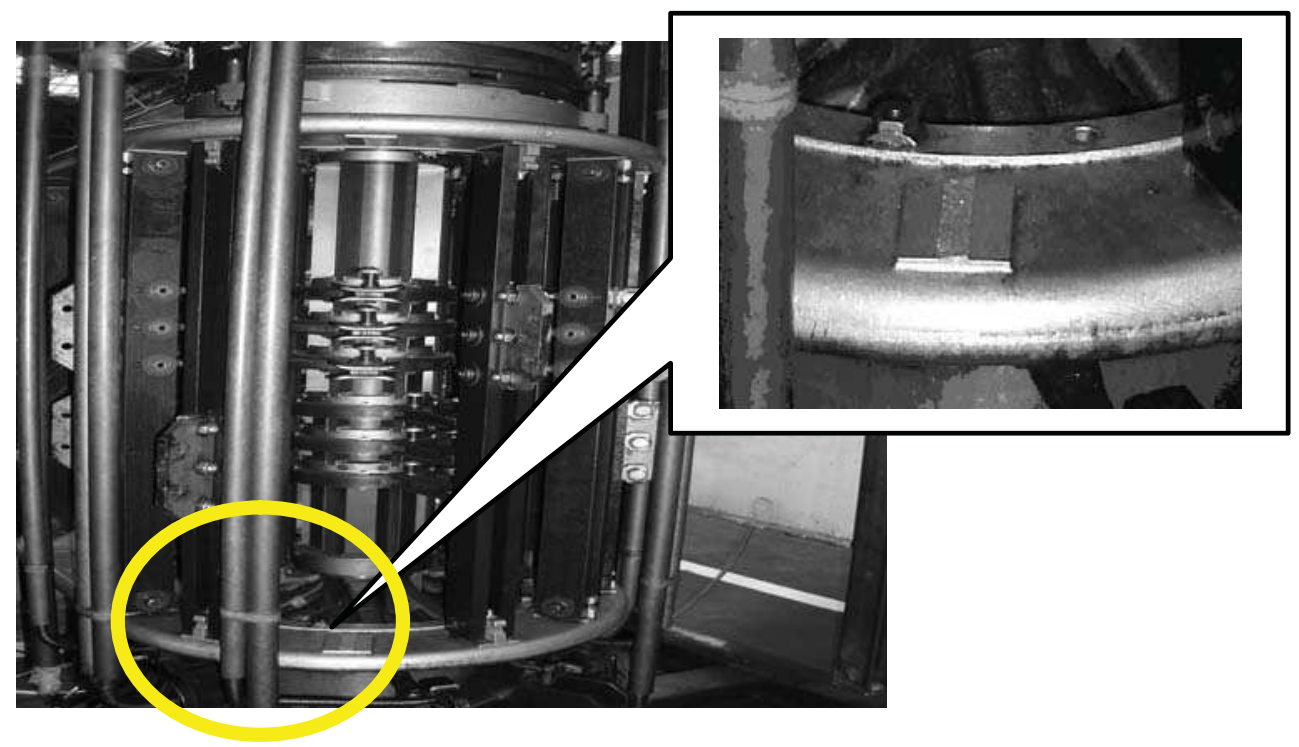

Fig. 4. Broken contact bar 


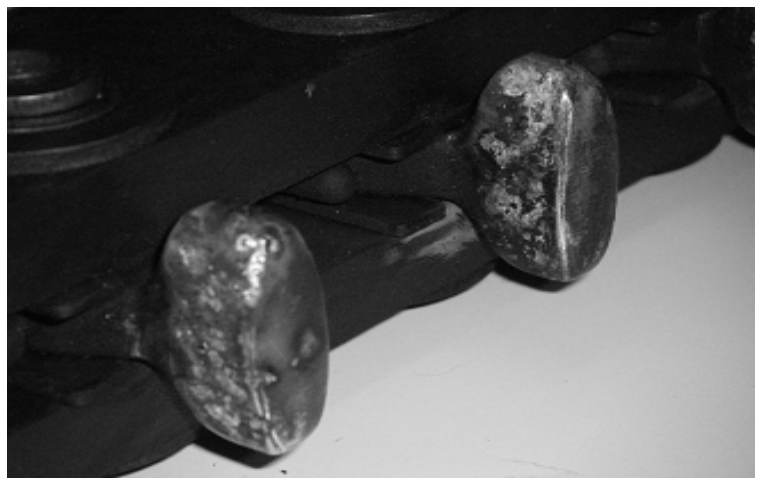

Fig. 5. Tap selector fixed contacts damaged by arcing

\section{Vibration signal treatment}

Vibration signal analysis is used to detect on load tap changer failures. According to ( P. Kang \& D. Birtwhistle, 1998) the main parameters for diagnosis are: Number of vibration bursts, vibration burst amplitude, time between vibration bursts.

When two consecutive changes are made from the same initial tap to the same final tap, the obtained records are not identical. Large differences can be observed in amplitudes and in time between vibration bursts. Consequently, some kind of signal processing must be used when using vibration monitoring to detect OLTC faults.

The OLTC vibration signals are subjected to the treatment process shown in Fig. 6. The purpose and meaning of each treatment is summarised below.

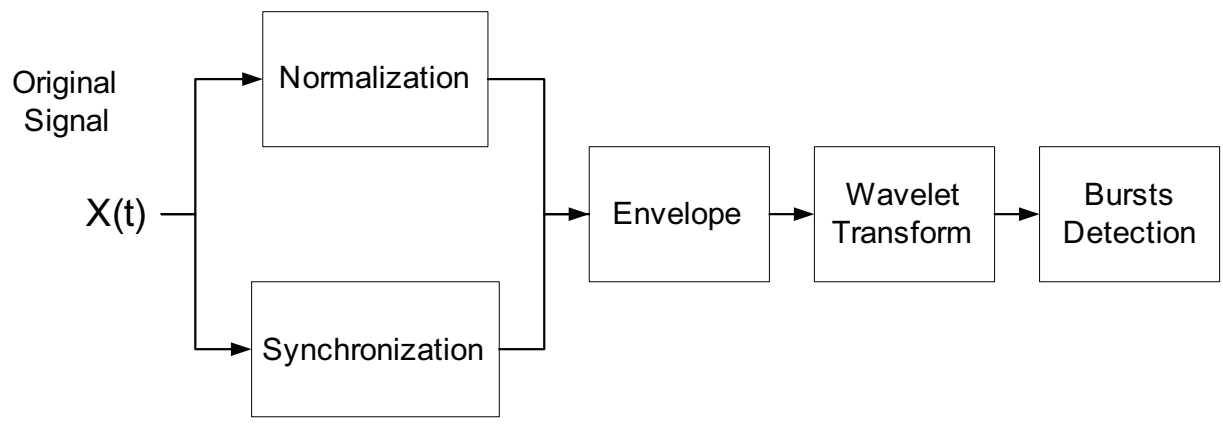

Fig. 6. Process for obtaining the wavelet envelope spectrum

\section{A. Normalization and synchronization of signals}

In first place vibration signals are synchronised, so that they start at the same time. Then, signals are normalised using their RMS value.

As in our study the sampling rate is $50 \mathrm{kS} / \mathrm{s}$, in a 10 s record there are 500000 samples (Fig.2). By eliminating the samples with no information will the signals are reduced to 267,001 269,001 samples. 


\section{B. Envelope analysis}

The main information in the vibration signal is in the signal envelope. So, once the vibration signals are normalised and synchronised, the Hilbert transform is used to obtain the envelope (A. I. Zayed., 1998).

The analytic signal corresponding to a real signal $x(t)$ is defined as $x(t)+j \bar{x}(t)$, where the real part of the analytical signal is the original signal and the imaginary part, $\bar{x}(t)$ is the Hilbert transform of $x(t)$. The magnitude of this complex analytical signal forms the signal envelope and is always a positive function.

As mentioned the vibration signal is not exactly the same when repeated a tap change. Even some spurious bursts can appear. To solve this problem the vibration signal is converted into energy with the same number of intervals for each input signal. The average energy signal is computed, obtaining signals containing bursts with a similar number of samples. For the correct detection of bursts present in the envelope of the vibration signal is divided into six time intervals, thus reducing the signal to 640 samples (Fig. 7).

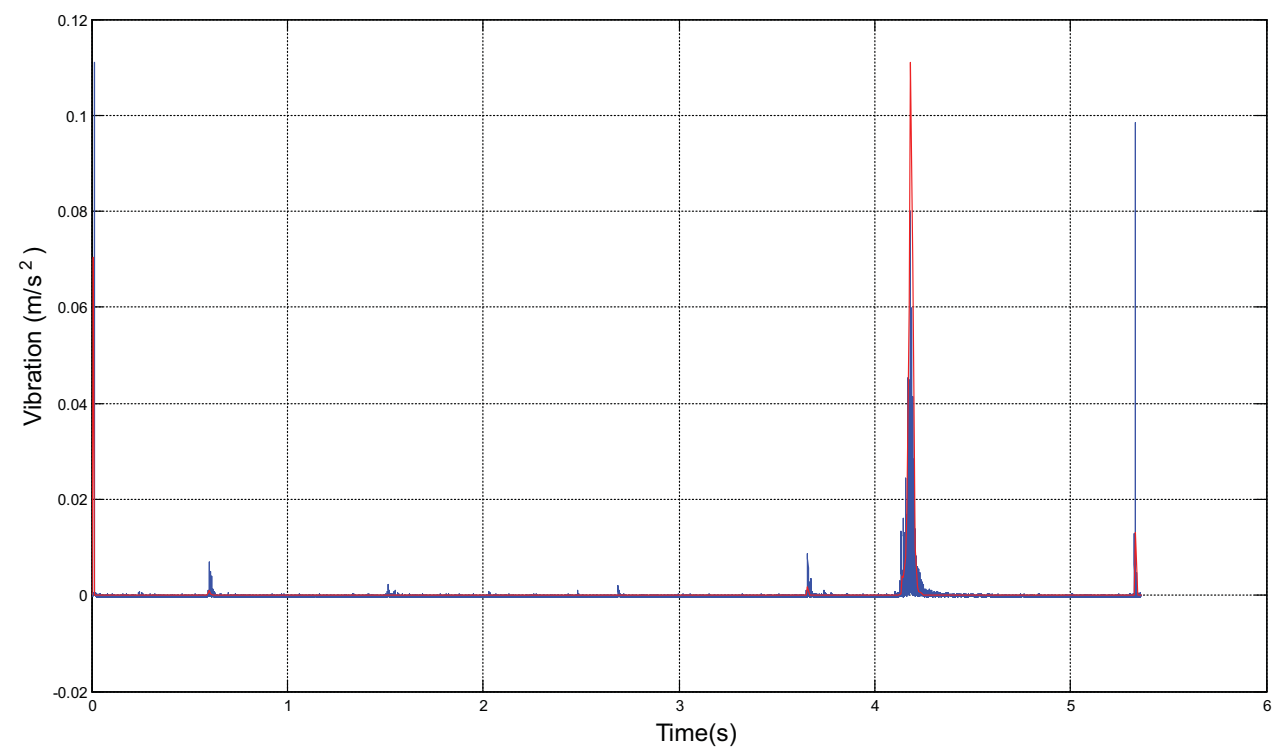

Fig. 7. Average energy of the envelope in regular time intervals

\section{Discrete wavelet transform}

Envelope analysis based on Hilbert transform is used as Wavelet decomposition preprocessing.

Discrete wavelet transform (DWT) is used to decompose a signal, through two types of filters (low pass and high pass filter). The number of times the signal is filtered is determined by the applied decomposition level. In this way, a set of coefficients (approximation and detail coefficients) are obtained at each decomposition level. Discrete wavelet transform (DWT) of a signal $\mathrm{f}(\mathrm{t})$ is defined by (S. Mallat, 1988): 


$$
\operatorname{DWTf}(t)=\sum_{-\infty}^{j} \sum d_{j}[n]+\sum_{n \in Z} a_{j}[n] \psi_{j n}, j \in Z
$$

$a_{j}[n]:$ Approximation coefficients

$d_{j}[n]$ : Detail coefficients

$\psi_{j n}$ : scaling function.

These coefficients represent part of the original signal, for certain frequency bands and time intervals.

For the implementation of discrete wavelet transform to the envelope of the vibration signal in a first instance we must select the mother wavelet and then decompose the signal. The signal is reconstructed using Inverse Wavelet Transform (IDWT).

\section{Mother wavelet selection}

In order to have an indicator relating the correlation between the processed signal and the selected mother wavelet Parseval's theorem is used. This indicator is the sum of the squared spectrum coefficients of the Fourier transform refer to frequency domain.

$$
\frac{1}{N} \sum|f[t]|^{2}=\sum\left|b_{k}\right|^{2}
$$

Where $N$ is the sampling period, and $b_{k}$ are the coefficients of the Fourier transform Spectrum.

Then, we use (1) and (2) to apply Parseval's theorem to the DWT application and we obtain (3)

$$
\frac{1}{N} \sum|f[t]|^{2}=\sum_{-\infty}^{j} \sum\left|d_{j}[n]\right|^{2}+\sum_{n \in Z}\left|a_{j}[n]\right|^{2}
$$

Parseval's theorem relates the energy of the signal $f(t)$ to the energy in each component and the wavelet coefficients.

Then we use (3) as a comparison index for evaluation of the different mother wavelets that can be used. Table 1 shows the value of the aforementioned index with different mother wavelets when using the original signal and when using the envelope.

\begin{tabular}{|c|c|c|c|}
\hline Wavelet & Type & $\begin{array}{c}\text { Index } \\
\text { (Signal) }\end{array}$ & $\begin{array}{c}\text { Index } \\
\text { (Envelope) }\end{array}$ \\
\hline Daubechies & db9 & 3500.103468 & 251.8379024 \\
\hline Symelet & sym8 & 3497.532913 & 250.7456702 \\
\hline Coiflet & coif5 & 3502.697888 & 253.4763404 \\
\hline Biortogonal & bior 3.1 & 498043.4396 & 2420.976428 \\
\hline Biortogonal & bior 3.3 & 20573.9404 & 639.0276636 \\
\hline
\end{tabular}

Table 1. The value of the aforementioned index with different mother wavelets 


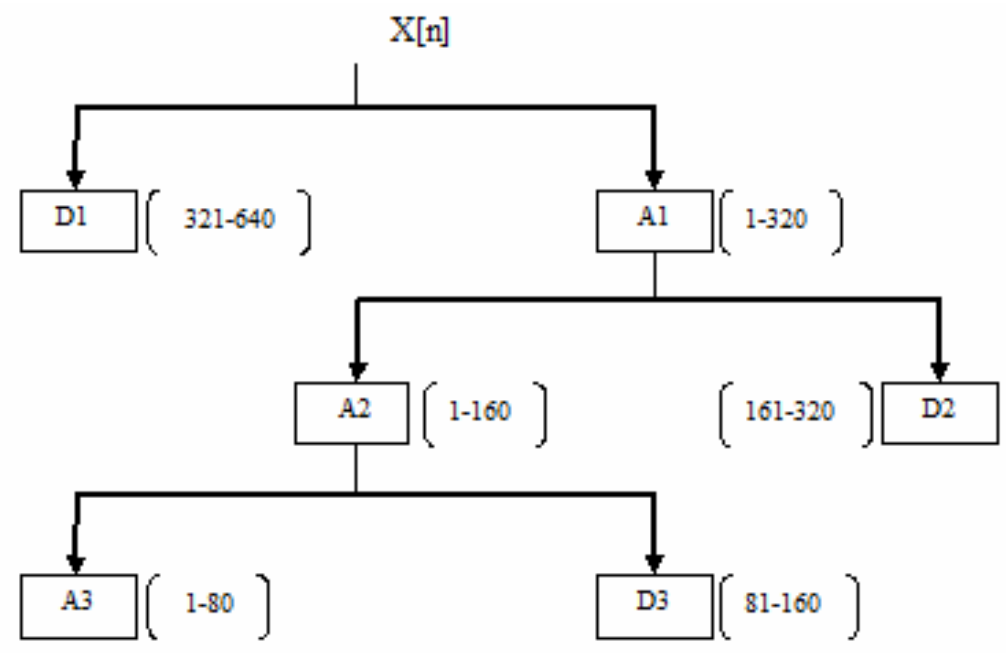

Fig. 8. Wavelet decomposition

From Table 1, it is evident that the best index when evaluating the envelope is the one obtained with the Biorthogonal Wavelet 3.1. Nevertheless, this mother wavelet is not square integrable (E. Rivas, et al.,2009), so the Fourier fast transform cannot be performed since it does not converge. Therefore, a pseudofrequency cannot be associated allowing us to relate one scale in the Wavelet domain with one frequency in the Fourier domain.

Then Bior 3.3 mother wavelet was chosen since this wavelet presents the greatest correlation index when compared to other mother wavelets and it allows characterizing the vibration signal.

Wavelet decomposition at level 3 (Fig. 8) is applied to the envelope of the energy signal (Fig. 7). Signal reconstruction from the coefficients of third level has a correlation of $94 \%$ with the original signal.

\section{Bursts detection}

Once discrete Wavelet Transform is performed, bursts are detected (Fig. 10). A smooth filtering based on threshold is used, to reduce noise and eliminate spurious bursts. To distinguish residual noise in the signal from the true burst, the energy present in the bursts are computed as the energy of residual noise is very low. The indicators used to evaluate the suitability threshold were:

- $\quad$ Preserved energy in the signal (Ep): Measures the proportion of energy preserved in the envelope signal after thresholding.

$$
E p=\frac{\sum_{i=1}^{N}\left[e n v_{t h}[i]\right]^{2}}{\sum_{i=1}^{N}[e n v[i]]^{2}} \times 100 \%
$$

Where env $=$ envelope and $\mathrm{env}_{\mathrm{th}}=$ smoothed envelope. 
- Mean Square Noise (MSE): This indicator is proportional to the distortion in the filtered signal, thus its value should be the lowest possible.

$$
M S E=\frac{1}{N} \sum_{i=1}^{N}\left[e n v[i]-e n v_{t h}[i]\right]^{2}
$$

- Signal Noise Ratio (SNR): This indicator measures the noise proportion referring to the signal.

$$
S N R(d b)=10 \log \frac{\sum_{i=1}^{N}[e n v[i]]^{2}}{\sum_{i=1}^{N}\left[e n v[i]-e n v_{t h}[i]\right]^{2}}
$$

The criterion to choose the threshold value is based on capturing the greatest percentage of energy with a low MSE and a suitable SNR. Fig. 9 shows Ep and MSE values as a function of threshold value.

From this figure it is deduced that the appropriate threshold value is within the range from $0.8 \%$ to $1.3 \%$ of the envelope RMS value.

In our case a threshold of $1 \%$ was used. The average values (72 vibration records) of process indicators were, $\mathrm{Ep}=97.59 \%, \mathrm{MSE}=1.28 \mathrm{E}-08$ with $\mathrm{SNR}=36.55 \mathrm{db}$. Fig. 9 shows the reconstructed vibration signal after applying the threshold.

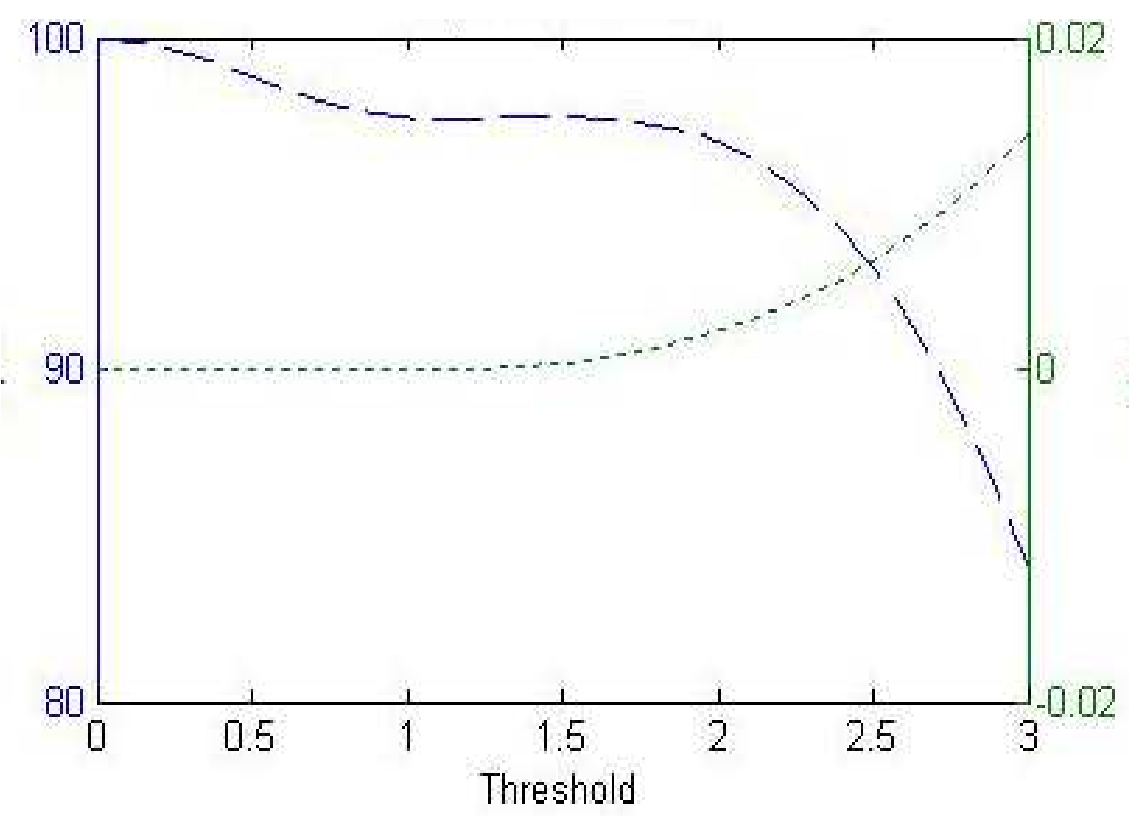

Fig. 9. Preserved energy versus threshold value (discontinuous line) and Mean Square Error (dotted line) vs. threshold 


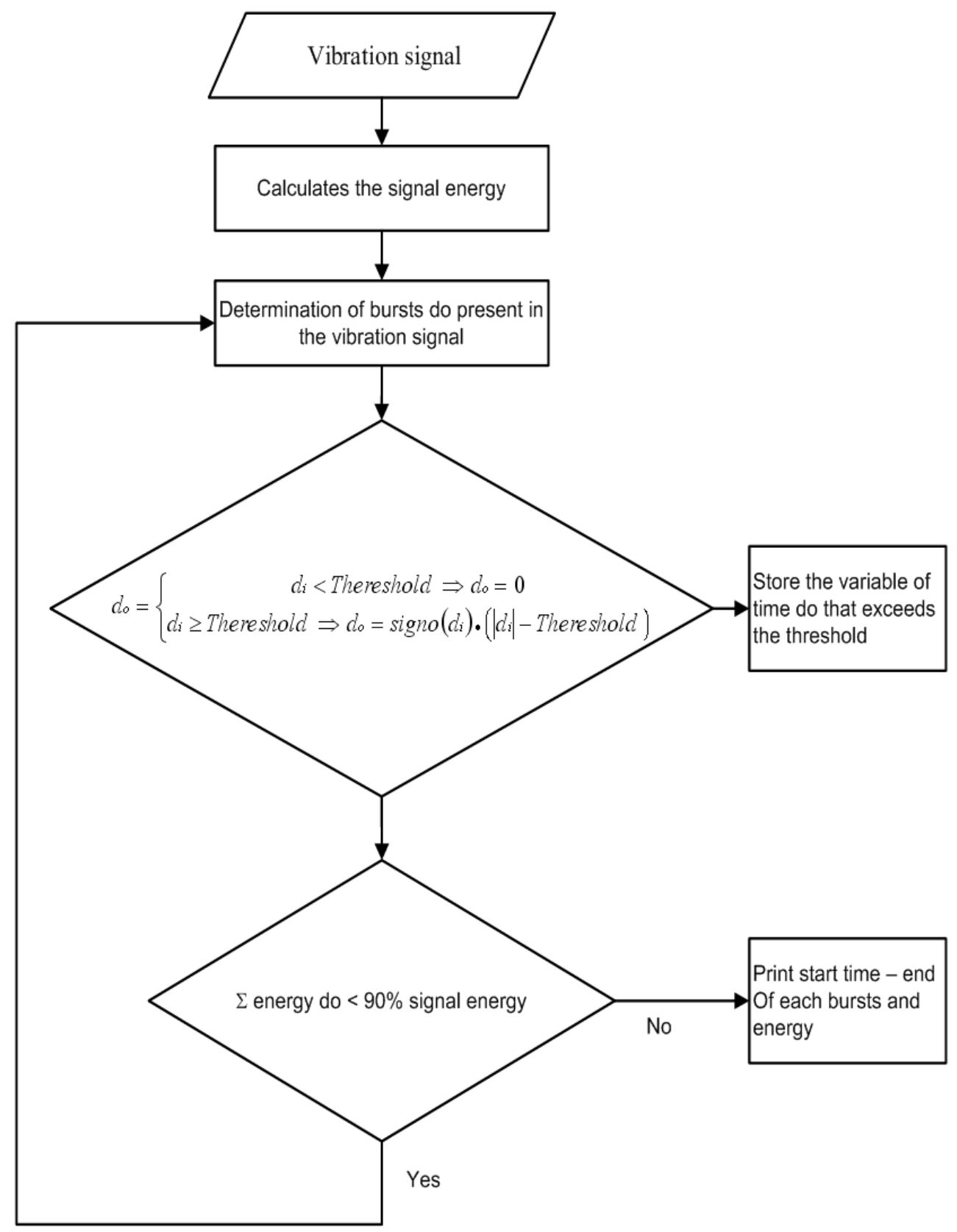

Fig. 10. Bursts detection 


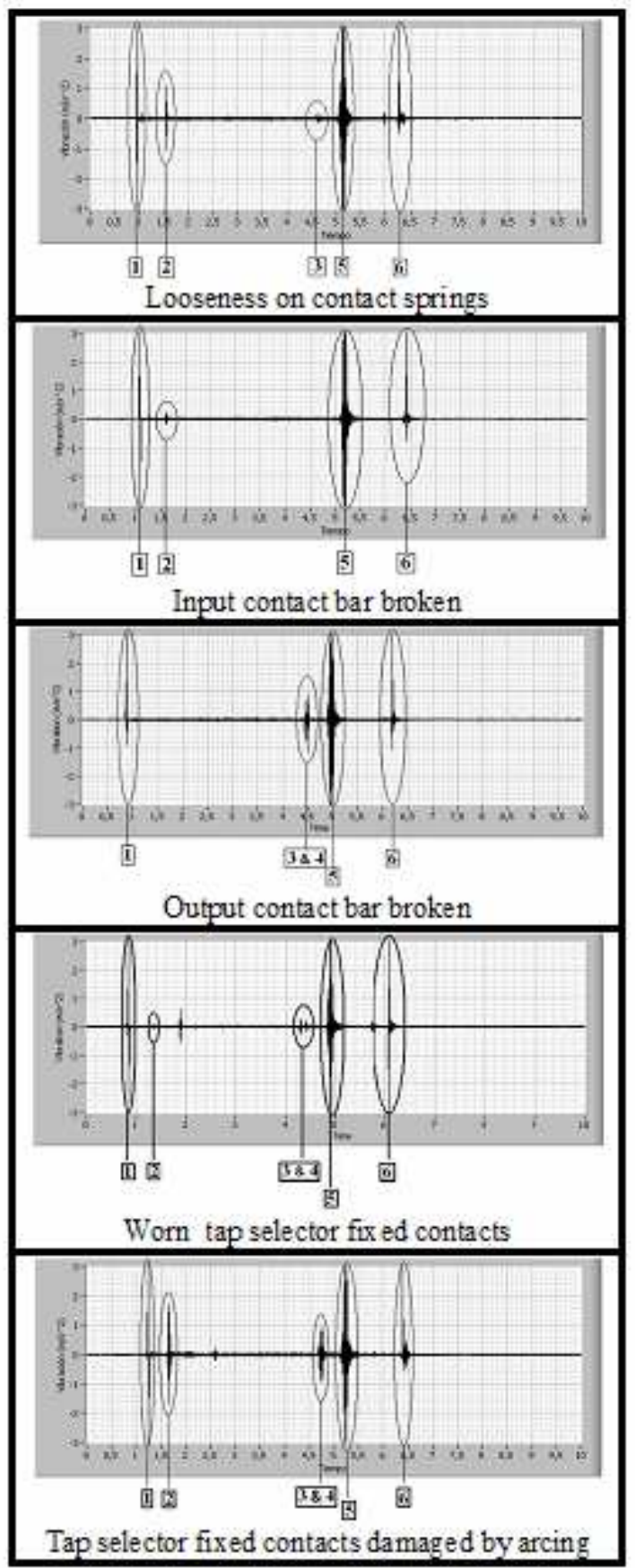

Table 2. Vibration signals for the simulated failures 


\begin{tabular}{|c|c|c|c|c|c|c|}
\hline CONDIIION & & t2-t1 & $\mathrm{t} 3-\mathrm{t}^{2}$ & $\mathrm{t} 4-\mathrm{t}^{3}$ & $t 5-t 4$ & $t 6-t^{5}$ \\
\hline \multirow{3}{*}{ GOOD } & Average time (s) & 0.61 & 3.08 & 0.12 & 0.59 & 1.18 \\
\hline & $\begin{array}{l}\text { Standard deviation } \\
\text { (s) }\end{array}$ & 0.08 & 0.01 & 0.01 & 0.07 & 0.22 \\
\hline & $\begin{array}{c}\text { Standard } \\
\text { deviation/Average } \\
\text { time }(\%)\end{array}$ & 12.7 & 0.30 & 9.33 & 13.16 & 18.7 \\
\hline \multirow{3}{*}{$\begin{array}{l}\text { LOOSENESS ON } \\
\text { CONTACT } \\
\text { SPRINGS }\end{array}$} & Average time (s) & 0.62 & 3.09 & & & 1.22 \\
\hline & $\begin{array}{l}\text { Standard deviation } \\
\text { (s) }\end{array}$ & 0.01 & 0.01 & & & 0.01 \\
\hline & $\begin{array}{c}\text { Standard } \\
\text { deviation/Average } \\
\text { time }(\%)\end{array}$ & 1.61 & 0.32 & & & 1.09 \\
\hline \multirow{3}{*}{$\begin{array}{l}\text { NPUT CONTACT } \\
\text { BAR BROKEN }\end{array}$} & Average time (s) & 0.57 & & & & 1.29 \\
\hline & $\begin{array}{l}\text { Standard deviation } \\
\text { (s) }\end{array}$ & 0.02 & & & & 0.01 \\
\hline & $\begin{array}{c}\text { Standard } \\
\text { deviation/Average } \\
\text { time }(\%)\end{array}$ & 3.5 & & & & 0.77 \\
\hline \multirow{3}{*}{$\begin{array}{l}\text { OUTPUT } \\
\text { CONTACT BAR } \\
\text { BROKEN }\end{array}$} & Average time (s) & & & & 0.55 & 1.31 \\
\hline & $\begin{array}{l}\text { Standard deviation } \\
\text { (s) }\end{array}$ & & & & 0.04 & 0.06 \\
\hline & $\begin{array}{c}\text { Standard } \\
\text { deviation/Average } \\
\text { time }(\%)\end{array}$ & & & & 7.23 & 4.56 \\
\hline \multirow{3}{*}{$\begin{array}{l}\text { WORN } \\
\text { CONTACTS }\end{array}$} & Average time (s) & 1.08 & 2.60 & 0.14 & 0.67 & 1.30 \\
\hline & $\begin{array}{l}\text { Standard deviation } \\
\text { (s) }\end{array}$ & 0.15 & 0.34 & 0.01 & 0.03 & 0.01 \\
\hline & $\begin{array}{c}\text { Standard } \\
\text { deviation/Average } \\
\text { time }(\%)\end{array}$ & 13.8 & 13.1 & 7.14 & 4.47 & 0.77 \\
\hline \multirow{3}{*}{$\begin{array}{l}\text { TAPSELECTOR } \\
\text { CONTACTS } \\
\text { DAMAGED BY } \\
\text { ARCING }\end{array}$} & Average time (s) & 0.43 & & & 0.39 & 1.19 \\
\hline & $\begin{array}{l}\text { Standard deviation } \\
\text { (s) }\end{array}$ & 0.01 & & & 0.05 & 0.01 \\
\hline & $\begin{array}{c}\text { Standard } \\
\text { deviation/Average } \\
\text { time }(\%)\end{array}$ & 2.32 & & & 12.82 & 0.84 \\
\hline
\end{tabular}

Table 3. Statistical Study

\section{Results}

Table 2 shows the vibration signature for some of the simulated failures. The study was carried out on 120 vibration signals, corresponding to 6 different conditions (Table 2) of the OLTC (20 signals for each condition).

Some diagnostic indicators were extracted starting from the vibration signal (frequency spectrum, wavelet coefficient comparison, etc). The best indicator to classify vibration signals was time between vibration bursts. As vibration signals are not repetitive a statistical study was carried out to prove the suitability of this indicator. Table 3 shows the results of the statistical study. As it is deduced from Table 3, time between vibration bursts differs 
significantly when failures do exist and when failures are absent. In certain types of failures some impulses (highlighted in grey in table 3) even disappear from the vibration signal.

\section{Conclusion}

It is of great importance to obtain indicators to assess the condition of high voltage equipment. Vibration signal can be used to assess the condition of a transformer OLTC.

Main diagnostic indicators can be obtained by using Wavelet Transform to signal vibration. The use of a mother wavelet with the highest correlation with the vibration signals allows for a higher preservation of the original signal energy (and even with respect to the smoothed signal). But this is not a guarantee for smoothing the obtained signal or spurious burst elimination.

In order to automatically obtain the bursts in the vibration envelope it is necessary to obtain wavelet coefficients of the signal. The proper election of those coefficients depends on the required information and the mother wavelet used and is obtained as a trade-off between the correlation of the envelope of the energy signal and the reconstructed signal.

After analyzing the ability of different diagnostic indicators (number of bursts, vibration burst amplitudes, burst energy, time between vibration bursts, frequency band of bursts) to properly classify different kind of OLTC failures, time between vibration bursts (and eventually burst appearance or disappearance) are proven the most suitable indicators.

\section{Acknowledgments}

This study has been funded by the Spanish Science and Technology Ministry (MCYT) under project no. DPI2009-07093.

\section{References}

L.A.L. de Almeida, M. Fontana, F.A. Wegelin, and L. Ferreira "A New Approach for Condition Assessment of On-Load Tap-Changers Discrete Wavelet Transform", Instrumentation and Measurement Technology Conference, 2005. Proceedings of the IEEE. Volume 1, 16-19 May 2005, pp. 653 - 656.

Simas, E.F., de Almeida, L.A.L., de Lima, A.C., "Vibration Monitoring of On-Load Tap Changers Using a Genetic Algorithm" Instrumentation and Measurement Technology Conference, 2005. Proceedings of the IEEE. Volume 3, 16-19, May 2005, pp. 2288 - 2293.

M. Foata, R. Beauchemin, and C. Rajotte, "On-line testing of on-load tap changers with a portable acoustic system," IEEE 9th International Conference on Transmission and Distribution Construction, Operation and Live-Line Maintenance Proceedings, pp. 293 - 298, Oct. 2001.

R. Jongen, P. Morshuis et al. "A statistical approach to processing power transformer failure data" 19th Int Conf on Electricity Distribution CIRED 2007 paper 546. Vienna May 2007.

a. P. Kang, D. Birtwhistle, J. Daly, and D. McCulloch, “Non-invasive on-line condition monitoring of on-load tap changers," in Proceedings of IEEE Power Engineering Society Winter Meeting, Singapore, 2000. 
b. P. Kang and D. Birtwhistle "Analysis Of Vibration Signals For Condition Monitoring Of Power Switching Equipment Using Wavelet Transform" (Proc of the IEEE-SP International Symposium on Time Frequency and time scale analysis 1998, Oct 1998, pp. 6-9)

S. Mallat, A Wavelet Tour of Signal processing. Academic Press, 1988.

E. Rivas, J. C. Burgos and J. C. Garcia-Prada. (2009, Condition assessment of power OLTC by vibration analysis using wavelet transform. IEEE Transactions on Power Delivery Vol 24 No 2, pp. 687-694. Abril 2009.

A. I. Zayed., Hilbert transform associated with the fractional fourier transform. Signal Processing Letters, IEEE 5(8), pp. 206-208. 1998. 


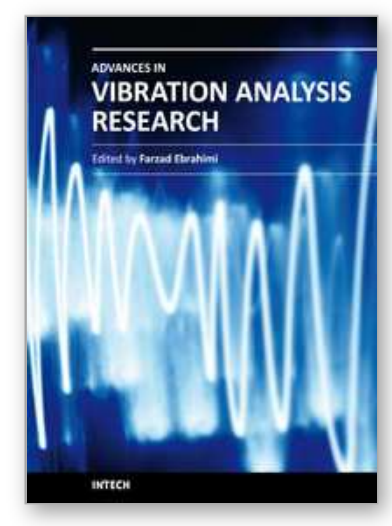

\author{
Advances in Vibration Analysis Research \\ Edited by Dr. Farzad Ebrahimi
}

ISBN 978-953-307-209-8

Hard cover, 456 pages

Publisher InTech

Published online 04, April, 2011

Published in print edition April, 2011

Vibrations are extremely important in all areas of human activities, for all sciences, technologies and industrial applications. Sometimes these Vibrations are useful but other times they are undesirable. In any case, understanding and analysis of vibrations are crucial. This book reports on the state of the art research and development findings on this very broad matter through 22 original and innovative research studies exhibiting various investigation directions. The present book is a result of contributions of experts from international scientific community working in different aspects of vibration analysis. The text is addressed not only to researchers, but also to professional engineers, students and other experts in a variety of disciplines, both academic and industrial seeking to gain a better understanding of what has been done in the field recently, and what kind of open problems are in this area.

\title{
How to reference
}

In order to correctly reference this scholarly work, feel free to copy and paste the following:

Edwin Rivas Trujillo, Juan C. Burgos Diaz and Juan C. Garcia-Prada (2011). Methodology for Vibration Signal Processing of an On-load Tap Changer, Advances in Vibration Analysis Research, Dr. Farzad Ebrahimi (Ed.), ISBN: 978-953-307-209-8, InTech, Available from: http://www.intechopen.com/books/advances-in-vibrationanalysis-research/methodology-for-vibration-signal-processing-of-an-on-load-tap-changer

\section{INTECH}

open science | open minds

\author{
InTech Europe \\ University Campus STeP Ri \\ Slavka Krautzeka 83/A \\ 51000 Rijeka, Croatia \\ Phone: +385 (51) 770447 \\ Fax: +385 (51) 686166 \\ www.intechopen.com
}

\author{
InTech China \\ Unit 405, Office Block, Hotel Equatorial Shanghai \\ No.65, Yan An Road (West), Shanghai, 200040, China \\ 中国上海市延安西路65号上海国际贵都大饭店办公楼 405 单元 \\ Phone: +86-21-62489820 \\ Fax: $+86-21-62489821$
}


(C) 2011 The Author(s). Licensee IntechOpen. This chapter is distributed under the terms of the Creative Commons Attribution-NonCommercialShareAlike-3.0 License, which permits use, distribution and reproduction for non-commercial purposes, provided the original is properly cited and derivative works building on this content are distributed under the same license. 